\title{
8 | Participation, inclusion and development under conditions of social mobilization'
}

\author{
VERA SCHATTAN COELHO AND
}

ARILSON FAVARETO

This chapter analyses processes of social mobilization and the dynamics of participatory forums in the Vale do Ribeira, Brazil, discussing the argument that mobilized actors and 'well-designed' institutions enable the inclusion of a broader spectrum of actors in political debates, as well as reducing the asymmetries between them, thereby facilitating the negotiation and agreement of politically and economically viable projects that may help to encourage development in the region.

The Vale do Ribeira Paulista is a poor region, made up of twenty-five municipalities located between two of the richest metropolitan regions in Brazil; 350,00o people live in the area, with a large number of traditional communities, such as indigenous groups, quilombola (rural Afro-Brazilian) communities, caiçaras (artisanal fishers and smallholders of mainly indigenous descent) and family farmers, many of whom are organized into associations. The region also contains the largest remaining area of Atlantic rainforest, covering two-thirds of the territory. In these circumstances there are inevitable tensions between, on the one hand, a demand for revitalizing the economy, based on the necessity of dealing with poverty, and on the other, the delicate problems of environmental control, due to the urgent need to preserve the native Atlantic rainforest.

This chapter focuses on two participatory forums active in the region and analyses how they have been dealing with these issues. The two cases are the Committee for the Management of Water Resources (CGRH) and the Consortium of Food Safety and Local Development (Consad). The two forums were observed in terms of how they dealt with two polemical regional issues: the proposal to build a big dam (the Tijuco Alto), a process that has been going on for more than a decade, and the definition of a programme of sustainable development capable of reconciling environmental conservation and growth in the local economy.

The literature on social participation, which will be looked at in more depth below, suggests that forums of this type may, in specific situations, open up space where various actors may take up positions concerning 
these polemical issues and negotiate alternatives. These situations depend on the institutional design, the degree of organization of civil society and the involvement of state actors. Nevertheless, if it is true that the presence, for example, of a 'good institutional design' facilitates inclusion, dialogue and negotiation, then it is also true that there still exists great difficulty in identifying what might be considered a 'good design', or even the conditions that would lead state actors and politicians responsible for the organization of these forums to choose this 'good' design instead of another favouring the reproduction of their own political coalition. This chapter works between these two perspectives, investigating the institutional conditions capable of fostering inclusion and dialogue, be that of the forums or of the political system. Furthermore, it questions the logic and the values that motivate the actors involved in the creation of these forums, a question that the literature is only beginning to broach. From the resulting observations the initial question will be revisited, since, if it is necessary to recognize which procedures are inclusive and democratic, it is equally important to identify the conditions that lead the actors responsible for the forums to adopt such procedures.

The analysis suggests that, during the period of research, the forums analysed re-created in the participatory sphere coalitions that were already present in the regional political scene, thereby acting as an extension of the party political game rather than as arenas where new arrangements of actors could agree on alternative projects. From a theoretical perspective, this result raises again the question of the origin and the evolution of institutions, in that it questions the mechanisms necessary for the creation of institutions explicitly designed to alter the status quo.

The chapter is divided into four main parts. The first section briefly sets out the theoretical debate concerning the relationship between participation and development and presents the questions and the methodology that guided the research. The second section presents a brief history of the Vale do Ribeiro to contextualize the debates about sustainable development, briefly describing the local civil society; highlighting the evolution of two important local organizations, the Movement of DamAffected People (MOAB) and the Union of Farming Families of the Vale do Ribeira (Sintravale); and finally presenting the controversy surrounding the dam. The third section deals with the two forums (CGRH and Consad), describing in detail the involvement of MOAB and Sintravale in them. The fourth section analyses the role of the forums in dealing with the two polemical issues mentioned above. The conclusion sets out the principal lessons that can be learnt from the experiences in the 
Vale do Ribeira concerning the relationship between participation and development.

\section{About social participation and development}

The literature that unites supporters of social participation in public policy is based upon two assumptions. The first is that the local population would be encouraged to participate because of a reduction in the costs involved in the process of political mobilization. This reduction would take place because local participatory bodies would be authorized by the public authorities to make substantive decisions about policy, and also because of the expectation that the citizen would participate using his or her own experience of the issues being discussed, therefore enabling resources to be used more efficiently. Problems of asymmetry, which might inhibit the inclusion of actors who have fewer resources, be they communicative, material or technical, would be successfully dealt with by good institutional engineering (Fung and Wright 2003; Fung 2004). The second argument is that providing the opportunity for the various actors involved to set out more explicitly their demands would allow those demands to become clearer and more understandable for the state actors, thereby highlighting local specificities that would encourage changes in the distribution of public funds, the way policies are implemented and the way regional agreements are reached; which in turn could contribute to the successful implementation of private initiatives, as well as public policies and programmes (Cunnil 1997; Abers 2001; World Bank 2001; UNDP 2002). The implicit causal mechanism consists in giving a voice to groups who have traditionally been marginalized, encouraging participation, negotiation and cooperation between various social segments, thereby increasing the trust and coordination between them, which in turn contributes to the promotion of development projects that coincide with their needs and interests (Avritzer 2003; Gaventa 2004).

Various texts question the viability of putting these mechanisms into action, pointing out the asymmetries that shape the relationships between the actors, as well as the excessive power of state actors in the participatory forums. Furthermore, they point out that special interest groups and party political groups can capture these forums. Some studies highlight a sort of 'dark side' of these forms of social assembly (Ray 2000, 2002): in general the selection of projects and the mechanisms for competition between territories, regions and social groups have the tendency to reinforce the positions of those who already have the best technical and political conditions, and thus are in a better position to obtain the 